\title{
Concomitant Medication Pre-specified
}

National Cancer Institute

\section{Source}

National Cancer Institute. Concomitant Medication Pre-specified. NCI Thesaurus. Code C113355.

An indication or description that concomitant medication was previously determined, characterized, or detailed. 